\title{
Contribution of social support to home-quarantined Chinese college students' well-being during the COVID-19 pandemic: the mediating role of online learning self-efficacy and moderating role of anxiety
}

\author{
Jihong Zhou' ${ }^{1} \cdot$ Hongying $\mathrm{Yu}^{2}$
}

Received: 18 June 2020 / Accepted: 23 August 2021 / Published online: 25 October 2021

(C) The Author(s), under exclusive licence to Springer Nature B.V. 2021

\begin{abstract}
Due to the outbreak of the COVID-19 pandemic, the implementation of quarantine policy led to an unprecedented home-quarantined living and online learning context for Chinese college students. This study aimed to investigate whether and how social support contributed to home-quarantined Chinese college students' well-being during the COVID-19 pandemic. In particular, this study examined the mediating role of online learning self-efficacy in explaining how social support contributed to home-quarantined Chinese college students' well-being. The study also examined the moderating effect of anxiety, which may buffer the effectiveness of social support and online learning self-efficacy in home-quarantined online learning contexts. Data include 2481 responses to an online questionnaire survey from home-quarantined Chinese college undergraduates. Data were analyzed by performing Partial Least Squares regression. Results showed that social support associated positively with home-quarantined Chinese college students' online learning self-efficacy and well-being. The results revealed a partial mediating effect of online-learning selfefficacy on the positive effect of social support on well-being. The moderating effect analysis found that the positive association of online learning self-efficacy with social support and well-being was stronger in home-quarantined Chinese college students who perceived no anxiety.
\end{abstract}

Keywords Social support · Well-being · Online learning self-efficacy · Anxiety · COVID-19 pandemic $\cdot$ Home-quarantined college students

Jihong Zhou

jihong.zhou@jcut.edu.cn

Extended author information available on the last page of the article 


\section{Introduction}

Since the corona virus disease 2019 (COVID-19) outbreak in Wuhan in late 2019, countries have imposed unprecedented quarantine policies to prevent the spread of the disease. While the quarantine policies efficiently reduced the risk of getting infected, it brought some negative impacts to people's psychological and even physical health as well (Organization, 2020). There have been studies reporting an increase in the levels of perceived stress, depression and anxiety among the quarantined population in such countries as UK, Italy and China (Flesia, Fietta, Colicino, Segatto, \& Monaro, 2020; Shevlin et al., 2020; Zhang et al., 2020). While most studies exploring the impact of COVID-19 on well-being focused on patients, medical staff and old adults as they tended to have a higher risk of getting infected (Bo et al., 2020), young college students drew little attention from researchers(Cao et al., 2020). Hence, factors uniquely influencing home-quarantined college students' well-being and how well common factors impacting college students' well-being in general environment seem to apply to this unique population during the health crisis warrants further research.

Literature has documented many predictors of college students' well-being in general life and study contexts. These predictors include self-esteem, academic self-efficacy, academic control, optimism, mindfulness, self-compassion, social support, recreational activities, and gender etc.(Ruthig et al., 2008; Stupnisky et al., 2013; Wang \& Castañeda-Sound, 2008; Wilson et al., 2020). Among these factors, the present study examined the impact of personal psychological factors (i.e., online learning self-efficacy and anxiety) and social/environmental factors (i.e., social support) on Chinese college students' well-being during the quarantine period. The selection of the aforesaid variables in this study was based on the ecological perspective (Bronfenbrenner, 1979), which holds that any accurate understanding of life-developmental outcomes such as college students' wellbeing requires a combined consideration of both personal and environmental factors.

This study has three objectives. The first objective is to examine whether social support is a significant predictor of home-quarantined Chinese college students' well-being during the COVID-19 pandemic. The second objective is to investigate whether online learning self-efficacy plays a mediating role in the relationship between social support and home-quarantined Chinese college students' well-being. The third objective is to explore whether the association of social support with online learning self-efficacy and well-being, and the relationship between online learning self-efficacy and well-being would diverge between home-quarantined Chinese college students who perceived anxiety and those who did not.

Our research is different from prior studies. Firstly, a plethora of studies have identified the important role of academic self-efficacy in facilitating the contribution of social support to college students' well-being (Soysa \& Wilcomb, 2013; Wang \& Castañeda-Sound, 2008). Our research is the first to examine the mediating role of online learning self-efficacy in the association between social 
support and college students' well-being. Online learning self-efficacy is unique in online learning contexts and has been identified as an important predictor of online students' academic performance (Yokoyama, 2019). However, to the best of our knowledge, although online learning self-efficacy has gained dominance in research about online learning, no research has examined its association with online learners' well-being.

Secondly, we take a special interest in examining whether the relationship among social support, online self-efficacy and well-being would diverge between home-quarantined college students with and without anxiety. To date, scarce study has taken anxiety as a contingent factor when examining the impact of social support on self-efficacy and well-being in online learning contexts. The findings from this study will add to literature about online learning and contribute to a better understanding of home-quarantined college students' well-being in public health crisis situations.

\subsection{Social support and college students' well-being}

Social support has gained dominant attention from researchers in the psychological and education fields in recent decades (Ma, 2019; Tomás et al., 2020). Social support refers to the perception or experience that one is cared for, esteemed and valued by others, and has a reliable social network available for help in times of need (Taylor, 2011). Sources of social support are diverse, but mainly from family, friends and significant others (Taylor, 2011). As Feeney and Collins (2015) have pointed out, "Close and caring relationships are undeniably linked to health and well-being at all stages in the life span"(p113). There is a general consensus that social support is a powerful contextual factor contributing to an individual's psychological and physical well-being (Renk \& Smith, 2007; Tomás et al., 2020). For college students, a large body of research has found a positive association between social support and psychological well-being in this unique population (Cicognani, 2011; Kong et al., 2012; Tinajero et al., 2019). The underlying rationale is that social support can impact people's cognitions, emotions, and behaviors in a way that promote positive affect (Cohen, Underwood, \& Gottlieb, 2000). Hence, social support is regarded as an effective social resource to help college students buffer stress and anxiety, beneficial for the development of their psychological well-being.

In our study, Chinese college students may encounter worry, loneliness and anxiety either caused directly by the risk of COVID-19 infection or indirect factors like the quarantine strategy as well as frustration in dealing with online learning, because this is the first time that they have had to take all the courses online quarantined at home. Support from parents, peers, and significant others like professors in this situation can serve as valuable resources to help them deal with these negative emotions, conducive to building up psychological and physical health. Given this, we propose that home-quarantined Chinese college students who perceive a high level of social support are more likely to be in better psychological and physical health than those with a low one. 
Hypothesis 1 Home-quarantined Chinese college students' perceived social support is positively associated with their well-being.

\subsubsection{Mediating role of online learning self-efficacy}

According to social cognitive theory, self-efficacy refers to an individual's judgement about his or her abilities to organize thoughts, feelings and actions to produce a desired outcome (Bandura, 1977). It is not what people can do, but what people perceive themselves to be able to do. Bandura (2010) proposed that self-efficacy is task and domain specific. Following this viewpoint, online education experts differentiate traditional classroom learning tasks and online learning ones to define online learning self-efficacy as an individual's perceptions of his or her abilities to successfully complete specific tasks required of online learners (Zimmerman \& Kulikowich, 2016). Online learning self-efficacy is a multi-facet concept and consists of three dimensions which are learning in an online environment, time management and technology use (Zimmerman \& Kulikowich, 2016). Students with a high level of online learning self-efficacy tend to exhibit more confidence in their capability of completing online learning courses, engaging in time management, and using computer and web-based technology necessary for online learning. Hence, there is a consensus that online learning self-efficacy is one of the strongest predictors of online learners' performance and retention (Abdous, 2019b; Shen et al., 2013; Zimmerman \& Kulikowich, 2016). For instance, Zimmerman and Kulikowich (2016) found that students with a high level of online learning self-efficacy are more likely to achieve better academic performance. Shen et al. (2013) observed that students' online learning self-efficacy predicted their satisfaction with online courses and opinions about participation in future online courses. Thus, it is important to consider the role of online learning self-efficacy when examining online learners' performance.

However, it is interesting to note that no research has explored the relationship between online learning self-efficacy and online learners' well-being. Despite this, literature has documented a well-established relationship between general academic self-efficacy and students' well-being in non-online learning environments (Pan et al., 2005; Soysa \& Wilcomb, 2013; Tong \& Song, 2004). For instance, Chemers et al. (2001) reported that academic self-efficacy is a predictor of first-year college students' health; in particular, when college students perceive a situation as challenging or threatening, the positive effect of academic self-efficacy on health is even stronger. Likewise, Wang and Castañeda-Sound (2008) found that first-generation college students report lower levels of academic self-efficacy and more somatic symptoms than their non-first-generation counters as the former tend to be less prepared for university environment and encounter more challenges than non-firstgeneration ones. These research findings suggest that when college students face a challenging and threatening environment, they are in great need of context-specific self-efficacy to cope with the overwhelming negative feelings and boost confidence to solve problems.

In our study, home-quarantined Chinese college students' living and learning environment can be quite challenging and threatening for them. On the one hand, 
since this is the first time for them to take all the courses online, they may be not well-prepared and feel it challenging to learn efficiently online due to their lack of online learning experience or technology skills necessary for online courses. On the other hand, they may also feel threatened by the risk of getting infected by COVID19. Taking these characteristics into account, we propose that home-quarantined college students who have more confidence in their ability to learn online, manage time efficiently and use technology necessary for online courses will be more able to allocate time appropriately, keep a balance between study and life, and even find time to do more physical exercises, which will finally lead to better psychological and physical well-being. Hence, given the widely accepted agreement about the impact of self-efficacy on the behavior, effort and time spent for dealing with environmental challenge and threat (Chen et al., 2019; Olson, 2015), we propose that.

Hypothesis 2 Home-quarantined Chinese college students' online learning self-efficacy relates positively to their well-being.

Next, we propose a positive association between social support and online learning self-efficacy. Previous studies noted when facing an unfamiliar online learning space, online students have problems in unlearning longstanding learning habits and engaging in new ways of learning (Abdous, 2019a). Although young college students nowadays are familiar with mobile phones and the internet, this familiarity does not necessarily guarantee their preparedness and skills necessary for online learning, to the detriment to their confidence in completing online learning tasks (Abdous, 2019b). When home-quarantined Chinese college students were taking all the courses online for the first time, it could be anticipated that they would encounter the same problems as general online students have experienced. Hence, social support from family members, friends and significant others like professors is supposed to help home-quarantined Chinese college students increase their confidence in dealing with these problems. Or it could also be possible that suggestions from family members, colleagues and professors can directly help them solve problems, which would result in an increase in their confidence in online learning as well. Although no prior research has explored the one-on-one relationship between social support and online learning self-efficacy, a large body of research has found a positive association between social support and academic self-efficacy (J.-y. Lee \& Ciftci, 2014; Zander et al., 2018), which predicts a possible relationship between social support and online learning self-efficacy. Given this, we regard online learning self-efficacy as a unique academic self-efficacy specific to online learning contexts to propose that:

Hypothesis 3 Home-quarantined Chinese college students' perceived social support relates positively to their online learning self-efficacy.

Lastly, Considering the critical role of self-efficacy in transforming social support into positive cognition, emotions, and behaviors (Kong et al., 2012), we combine the aforesaid three hypothesis together and expect a mediating role of online 
self-efficacy in the impact of social support on home-quarantined Chinese college students' well-being, leading to the following hypothesis:

Hypothesis 4 Home-quarantined Chinese college students' online learning self-efficacy mediates the association between perceived social support and well-being.

\subsection{Moderating role of anxiety}

Various factors result in college students' feelings of anxiety (Bates \& Khasawneh, 2007). In general, college students' anxiety is often triggered by uncertainty and low learning effectiveness (Abdous, 2019a). In online learning contexts, online learners' anxiety is mostly caused by factors related to online learning, including unpreparedness for online courses, a low computer confidence or skills, feelings of loneliness and isolation, inability to manage the course tasks, and low control of locus due to distractions online (Abdous, 2019b; Bates \& Khasawneh, 2007; Saadé, Kira, $\&$ Nebebe, 2013). Feelings of anxiety decrease students' confidence in completing online courses and is inversely associated with their academic performance and well-being (Sun \& Rueda, 2012).

Research has found that college students' feelings of anxiety are often negatively related to social support (Cao et al., 2020; Crockett et al., 2007), online learning self-efficacy (Bates \& Khasawneh, 2007) and well-being (Kumaraswamy, 2013). Crockett et al. (2007) reported that college students who perceived high levels of anxiety received less social support from family members and teachers. Bates and Khasawneh (2007) observed that college students feeling more anxiety reported low academic self-efficacy. Given the previous findings that college students perceived less anxiety tend to receive more social support and have higher academic efficacy, we anticipate a stronger effect of social support on online learning self-efficacy and well-being among home-quarantined Chinese college students without anxiety than those with anxiety. For home-quarantined Chinese college students feeling anxiety, they may be less willing to expose their negative affectivity to friends, family members, and significant others, resulting in less effective help from social support, which is not conducive to the development of online learning self-efficacy and well-being.

Likewise, as college students with low levels of anxiety are reported to have higher self-efficacy and better well-being (Soysa \& Wilcomb, 2013), we anticipate a stronger effect of online learning self-efficacy on well-being among home-quarantined Chinese college students without anxiety than those with anxiety. We believe that the buffering role of anxiety in the development of online learning self-efficacy and well-being might weaken the strength of the impact of online learning self-efficacy on well-being.

Hypothesis $\mathbf{5 a}$ The effect of social support on online learning self-efficacy is likely to be stronger among home-quarantined Chinese college students without anxiety than those with anxiety. 
Hypothesis 5b The effect of social support on well-being is likely to be stronger among home-quarantined Chinese college students without anxiety than those with anxiety.

Hypothesis 5c The effect of online learning self-efficacy on well-being is likely to be stronger among home-quarantined Chinese college students without anxiety than those with anxiety

\section{Methods}

\subsection{Participants and procedures}

This study was conducted in a public university in Hubei province, central part of China. During the spring semester from March to July in 2020, all the college students in Hubei province were quarantined at home due to the outbreak of COVID19. They took all the courses online which were scheduled to be taught on campus. The survey was conducted on Wenjuanxing, a professional survey website in China often used by Chinese researchers to conduct surveys. Students' participation was completely voluntary, and the participants were assured of anonymity and confidentiality.

In total, 2488 undergraduates participated in the survey. After deleting the responses from seniors who took no courses this semester, 2481 responses are usable for data analysis. The respondents came from 12 majors and took an average of 8.14 courses online this semester with the range from 1 to 10 . The average age of the respondents was 19.57 , with the youngest ones aged at 18 and the oldest ones at 25. Regarding gender, $67.1 \%(n=1665)$ of them were females and $32.9 \%(n=816)$ were males. Regarding their academic year, $54.3 \%(\mathrm{n}=1348)$ of them were freshmen, $42.2 \%(n=1047)$ were sophomores and 3.5\% $(n=86)$ were juniors. During the quarantine time, $96.7 \%(\mathrm{n}=2398)$ of the respondents stayed with their family members. More detailed information about the respondents is reported in Table 1.

\subsection{Measures}

We adopted validated measures from the literature in our study. We followed translation and back-translation procedures to ensure the quality and validity of instruments in Chinese (Hult et al., 2008). Before the data collection on a large scale, we conducted a pilot test among a group of freshmen. We made minor adjustments to the wording of statements according to their feedback to ensure the meaning of each statement was clear.

Social support was assessed with the Multidimensional Scale of Perceived Social Support developed by Zimet et al. (1988). The twelve-item scale consists of three subscales measuring the perceived level of support from family members, friends, and significant others. Responses were scored on a 5-point Likert scale ranging from 1(totally disagree) to 5 (totally agree). 
Table 1 Descriptive statistics of the respondents

\begin{tabular}{|c|c|}
\hline Characteristics & Descriptive statistics \\
\hline Age (in years) & $\begin{array}{l}\text { Mean: } 19.57 \\
\text { Standard Deviation: } 1.028\end{array}$ \\
\hline Gender & $\begin{array}{l}\text { Male: } 816(32.9 \%) \\
\text { Female: } 1665(67.1 \%)\end{array}$ \\
\hline Academic year & $\begin{array}{l}\text { Freshman: } 1348(54.3 \%) \\
\text { Sophomore: } 1047(42.2 \%) \\
\text { Junior: } 86(3.5 \%)\end{array}$ \\
\hline Major & $\begin{array}{l}\text { Medical Science: } 517(20.8 \%) \\
\text { Primary Education: } 414(16.7 \%) \\
\text { Foreign Language: } 262(10.6 \%) \\
\text { Arts: } 218(8.8 \%) \\
\text { Telecommunication Engineering: } 179(7.2 \%) \\
\text { Computer: } 177 \text { (7.1\%) } \\
\text { Biology Engineering: } 162(6.5 \%) \\
\text { Machinery: } 147 \text { (5.9\%) } \\
\text { Economics \&Management : } 143(5.8 \%) \\
\text { Mass Media: } 109 \text { (4.4\%) } \\
\text { Mathematics \&Physics: } 81(3.3 \%) \\
\text { Chemical Engineering: } 72(2.9 \%)\end{array}$ \\
\hline During the COVID-19 quarantined time, stay with & $\begin{array}{l}\text { Family members: } 2398(96.7 \%) \\
\text { Cousins: } 9(0.4 \%) \\
\text { Friends: } 18(.7 \%) \\
\text { Alone: } 55(2.2 \%) \\
\text { Other: } 1(0.0 \%)\end{array}$ \\
\hline $\begin{array}{l}\text { Total Number of online courses taken during COVID- } \\
19\end{array}$ & $\begin{array}{l}\text { Mean: } 8.14 \\
\text { Standard Deviation: } 1.242\end{array}$ \\
\hline anxiety & $\begin{array}{l}\text { With anxiety: } 1634(65.9 \%) \\
\text { Without anxiety: } 847(34.1 \%)\end{array}$ \\
\hline Sources of anxiety & $\begin{array}{l}\text { Lack of face-face time with faculty: } 840(51.3 \%) \\
\text { Risk of online distraction (waste time on social } \\
\text { media): } 1365 \text { (83.4) } \\
\text { Lack of classroom environment: } 1278(78.1 \%) \\
\text { Lack of feedback from faculty: } 258(15.8 \%) \\
\text { Lack of interaction with classmates: } 492(30.1 \%) \\
\text { Lack of immediate classroom interaction with } \\
\text { faculty and classmates: } 752 \text { (45.9\%) } \\
\text { Risk of getting infected with COVID-19:235 } \\
\text { (14.4\%) } \\
\text { Worries about family members' getting infected } \\
\text { with COVID-19:245 (15\%) }\end{array}$ \\
\hline
\end{tabular}


Online learning self-efficacy was assessed with the Online Learning Self-Efficacy Scale (OLSES) by Zimmerman and Kulikowich (2016). The scale is suitable for online learning contexts with different student groups with and without online learning experience (Yavuzalp \& Bahcivan, 2020). The scale has 22 items in total and consists of three subscales measuring self-efficacy in terms of learning in the online environment (7-item), time management(3-item), and technology use(12-item). The respondents were asked to indicate their beliefs about how well they could perform the tasks on a six-point scale. A rating of 1 indicated that the respondents believed that they could perform the task poorly and a rating of 6 indicated that they believed that they could perform the task at an expert level.

Well-being was assessed by two items measuring college students' psychological and physical health. The two items are "How would you rate your physical health right now?" and "How would you rate your psychological health right now?". Responses were scored on a 5-point Likert scale ranging from 1(very poor) to 5 (very good). Such a practice has been widely adopted by researchers in psychology and education fields (Hall et al., 2006; Stupnisky et al., 2013).

Anxiety was a dummy variable. The item was "Has online learning during the quarantined time caused anxiety to you?" We coded this variable as 1 if the respondent reported "yes", as 0 if the respondent reported "no". To have a better understanding of causes of anxiety, the respondents who reported "yes" were further asked to indicate detailed sources of anxiety. The list of sources of anxiety was based on literature review and adjusted after a pilot test. Respondents were provided a chance of adding their own source of anxiety. The detailed information about sources of anxiety was presented in Table 1.

\subsection{Data analysis}

We used a Partial Least Squares Structural Equation Modeling (PLS-SEM) approach to analyze the data and estimate the proposed model. Chin (2010) argued that PLSSEM is advantageous in analyzing complex models with a high number of indicators and constructs. Such an advantage of PLS-SEM matches the complexity of the proposed model in this study which includes a mediation analysis and three moderation analyses. In addition, the number of indicators for online learning self-efficacy is as much as 22, which suggests that PLS-SEM is an appropriate data analysis tool for this study. Warp-PLS version 7.0 was used to conduct a PLS regression analysis (Kock, 2017).

\section{Results}

\subsection{Measurement model}

A set of preliminary tests were conducted to ensure that all the latent constructs had satisfactory psychometric properties. First, convergent validity was assessed via factor loadings. Results of factor loadings for all the latent constructs (shown 
Table 2 Factor loadings

\begin{tabular}{|c|c|c|c|c|c|}
\hline $\begin{array}{l}\text { Social } \\
\text { support(spt) }\end{array}$ & & $\begin{array}{l}\text { Online learning self- } \\
\text { efficacy(ols) }\end{array}$ & & Well-being & \\
\hline spt1 & $(0.767)$ & ols 1 & $(0.796)$ & Physical health & $(0.920)$ \\
\hline spt2 & $(0.829)$ & ols2 & $(0.796)$ & Psychological health & $(0.920)$ \\
\hline spt3 & $(0.808)$ & ols3 & $(0.734)$ & & \\
\hline spt4 & $(0.833)$ & ols 4 & $(0.778)$ & & \\
\hline spt5 & $(0.860)$ & ols 5 & $(0.748)$ & & \\
\hline spt6 & $(0.834)$ & ols6 & $(0.821)$ & & \\
\hline spt7 & $(0.820)$ & ols7 & $(0.814)$ & & \\
\hline spt8 & $(0.801)$ & ols8 & $(0.825)$ & & \\
\hline spt9 & $(0.822)$ & ols9 & $(0.764)$ & & \\
\hline spt10 & $(0.834)$ & ols10 & $(0.842)$ & & \\
\hline spt11 & $(0.775)$ & ols11 & $(0.836)$ & & \\
\hline \multirow[t]{11}{*}{ spt12 } & $(0.825)$ & ols12 & $(0.836)$ & & \\
\hline & & ols13 & $(0.704)$ & & \\
\hline & & ols14 & $(0.831)$ & & \\
\hline & & ols 15 & $(0.816)$ & & \\
\hline & & ols 16 & $(0.811)$ & & \\
\hline & & ols17 & $(0.833)$ & & \\
\hline & & ols18 & $(0.805)$ & & \\
\hline & & ols19 & $(0.838)$ & & \\
\hline & & ols 20 & $(0.849)$ & & \\
\hline & & ols 21 & $(0.751)$ & & \\
\hline & & ols 22 & $(0.831)$ & & \\
\hline
\end{tabular}

in Table 2) were above 0.7, indicating satisfactory convergent validity (Hair, Black, Babin, Anderson, \& Tatham, 2006). Second, discriminant validity was assessed by comparing the square root of the average variance extracted (AVE) with its corresponding correlations to other constructs. The square root of AVE for each construct exceeding its correlation with any other construct supports satisfactory discriminant validity (Fornell \& Larcker, 1981). The results shown in Table 3 confirmed that all the square roots of AVEs met this requirement. In addition, the heterotrait-monotrait (HTMT) ratios were used to assess discriminant validity as well (Henseler et al., 2015). The results in Table 4 showed that all the HTMTs were lower than 0.85 , meeting the conservative threshold suggested by Kline (2011). It further confirmed satisfactory discriminant validity. Third, construct reliability was assessed via Cronbach's alpha coefficient and composite reliability coefficient. The results in Table 3 indicate that both Cronbach's alpha coefficient and composite reliability coefficients of all constructs were above 0.7 , suggesting satisfactory reliability (Nunnally, 1978).

Multicollinearity was evaluated by using full variance inflation factor (VIF) statistics. To confirm that multicollinearity is not a serious issue, the full VIF 
Table 3 Correlations among variables and square roots of average variance extracted

\begin{tabular}{llllllll}
\hline Variables & $\begin{array}{l}\text { Cronbach's } \\
\text { Alpha coef- } \\
\text { ficient }\end{array}$ & $\begin{array}{l}\text { Composite } \\
\text { reliability } \\
\text { coefficient }\end{array}$ & $\begin{array}{l}\text { Social sup- } \\
\text { port }\end{array}$ & $\begin{array}{l}\text { Online } \\
\text { learning } \\
\text { self-efficacy }\end{array}$ & Well-being & Anxiety & Gender \\
\hline $\begin{array}{c}\text { Social sup- } \\
\text { port }\end{array}$ & .955 & .960 & $(.818)$ & & & & \\
$\begin{array}{c}\text { Online } \\
\text { learning }\end{array}$ & .974 & .976 & $.554^{* * *}$ & $(.804)$ & & & \\
$\begin{array}{l}\text { self-effi- } \\
\text { cacy }\end{array}$ & & & & & & & \\
Well-being & .818 & .917 & $.441^{* * *}$ & $.489^{* * *}$ & $(.920)$ & & \\
Anxiety & $\mathrm{n} / \mathrm{a}$ & $\mathrm{n} / \mathrm{a}$ & $-202^{* * *}$ & $-287^{* * *}$ & $-265^{* * *}$ & $(1.000)$ & \\
Gender & $\mathrm{n} / \mathrm{a}$ & $\mathrm{n} / \mathrm{a}$ & $.099^{* * *}$ & .006 & .018 & -030 & $(1.000)$ \\
Age & $\mathrm{n} / \mathrm{a}$ & $\mathrm{n} / \mathrm{a}$ & .001 & $.049^{*}$ & .037 & $-043^{*}$ & -150 \\
\hline
\end{tabular}

$* * * P<.001 ; * * p<.01 ; * p<.05$;

Square roots of average variance extracted of latent variables are shown in the parentheses; gender dummy variable (male $=1$; female $=0$ ), anxiety dummy variable (with anxiety $=1$; without anxiety $=0$ )

Table 4 Heterotrait-monotrait (HTMT) result

\begin{tabular}{lll}
\hline & Social support & Online learning self-efficacy \\
\hline $\begin{array}{l}\text { Online } \\
\text { learning self- } \\
\text { efficacy }\end{array}$ & .576 & \\
& $p<.001$ & \\
& $\mathrm{CI}_{.900}[0.543 ; 0.608]$ & \\
Well-being & .499 & .548 \\
& $p<.001$ & $p<.001$ \\
& $\mathrm{CI}_{.900}[0.467 ; 0.531]$ & $\mathrm{CI}_{900}[0.516 ; 0.581]$ \\
\hline
\end{tabular}

must be lower than 3.3 (L. Lee et al., 2011). The results showed that the full VIFs of the latent variables ranged from 1.028 to 1.670 , indicating that multicollinearity was not a problem in this study. In addition, Kock and Lynn (2012) argued that the full collinearity test could be used to check whether common method bias (CMB) was a problem in the PLS model analysis. The full VIF value less than 3.3 was a conservative criterion to justify $\mathrm{CMB}$ is not a problem. Results of full VIF confirmed that CMB was likely not a serious issue in our study.

\subsection{Hypotheses testing}

Figure 1 presents the results of the PLS analysis. All fit indices of the PLS model estimation, including the average path coefficient $(\mathrm{APC}=0.161 ; \mathrm{p}<0.001)$, average r-squared $(\mathrm{ARS}=0.297 ; \mathrm{p}<0.001)$, average adjusted $\mathrm{R}$-squared $(\mathrm{AARS}=0.296$; $\mathrm{p}<0.001$ ), average full collinearity $(\mathrm{AFVIF}=1.352$; good if $<3.3$ ), Tenenhaus 


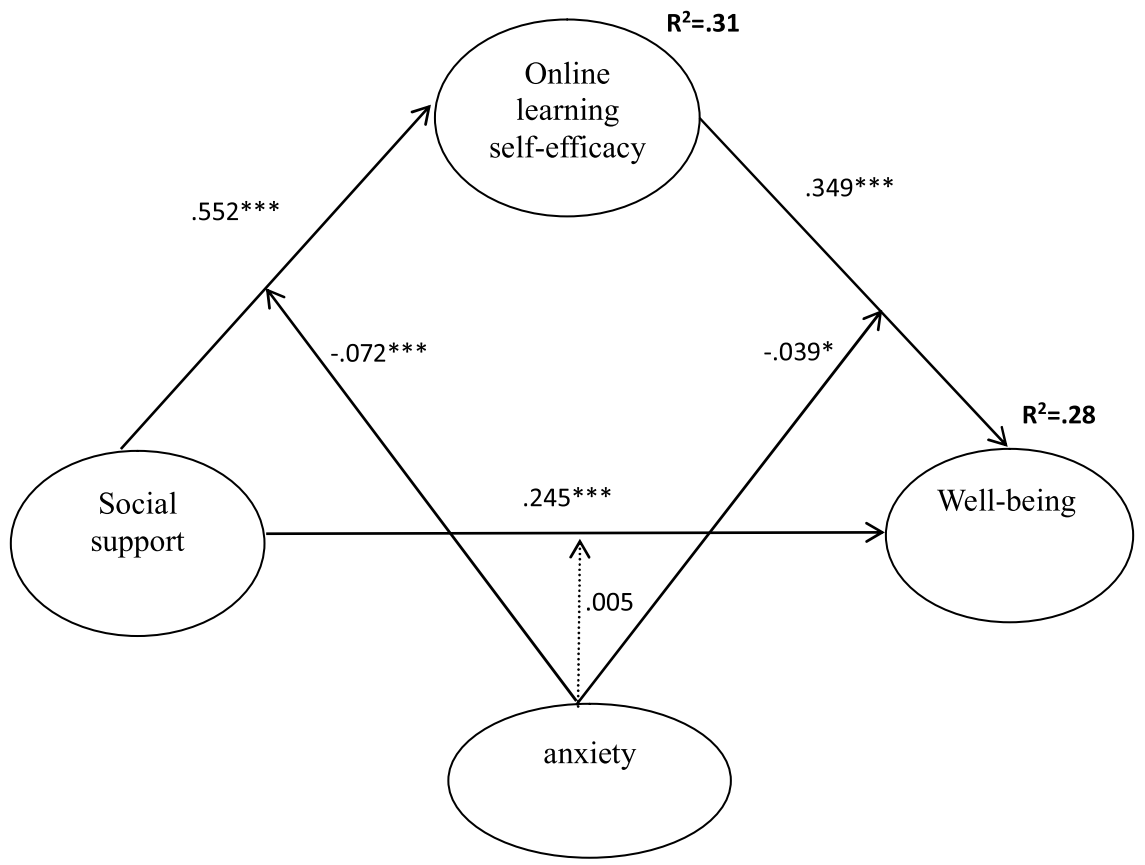

Fig. 1 Results from PLS analysis Notes: * $p<.05$; ** $p<.01$; *** $p<.001$ Standardized coefficients are reported. Adjusted R-square values are reported. Solid lines indicate significant paths. Dotted lines indicated insignificant paths

$\mathrm{GoF}(\mathrm{GoF}=0.516$, large $>=0.36)$, Sympson's paradox ratio $(\mathrm{SPR}=0.750$; good if $>=0.70)$, r-square contribution ratio $(\mathrm{RSCR}=0.999$; good if $>=0.90)$, and statistical suppression ratio ( $\mathrm{SSR}=1.000$; good if $>0.70$ ), nonlinear bivariate causality direction ratio $(\mathrm{NLBCDR}=1.000$; good if $>=0.70$ ) were satisfactory.

As indicated in Fig. 1, social support associated positively with well-being (H1: $\beta=0.245 ; \mathrm{p}<0.001)$ and online learning self-efficacy $(\mathrm{H} 2: \beta=0.552 ; p<0.001)$. Hence, Hypotheses 1 and 2 were supported. Online learning self-efficacy had a statistically significant positive association with well-being (H3: $\beta=0.349, p<0.001)$, supporting Hypothesis 3 .

Hypothesis 4 proposed that online learning self-efficacy would mediate the positive association between social support and well-being. The mediating effect was assessed by conducting the indirect and total effect analysis in WarpPLS suggested by Kock (2014). First, the indirect association between social support and wellbeing linked by online-learning self-efficacy is statistically significant $(\beta=0.193$; $\left.p<0.001 ; \mathrm{f}^{2}=0.085\right)$. Second, the direct association between social support and well-being is also significant $\left(\beta=0.441 ; p<0.001, \mathrm{f}^{2}=0.108\right)$. Finally, the total association between social support and well-being, which combines the direct and indirect association, is significant $\left(\beta=0.437 ; p<0.001 ; \mathrm{f}^{2}=0.193\right)$. Together, these findings show that the relationship between social support and well-being was partially mediated by online learning self-efficacy (Kock \& Gaskins, 2014). Moreover, as indicated by the $\mathrm{f}^{2}$ coefficient for the total association $\left(\mathrm{f}^{2}=0.193\right)$, this total 


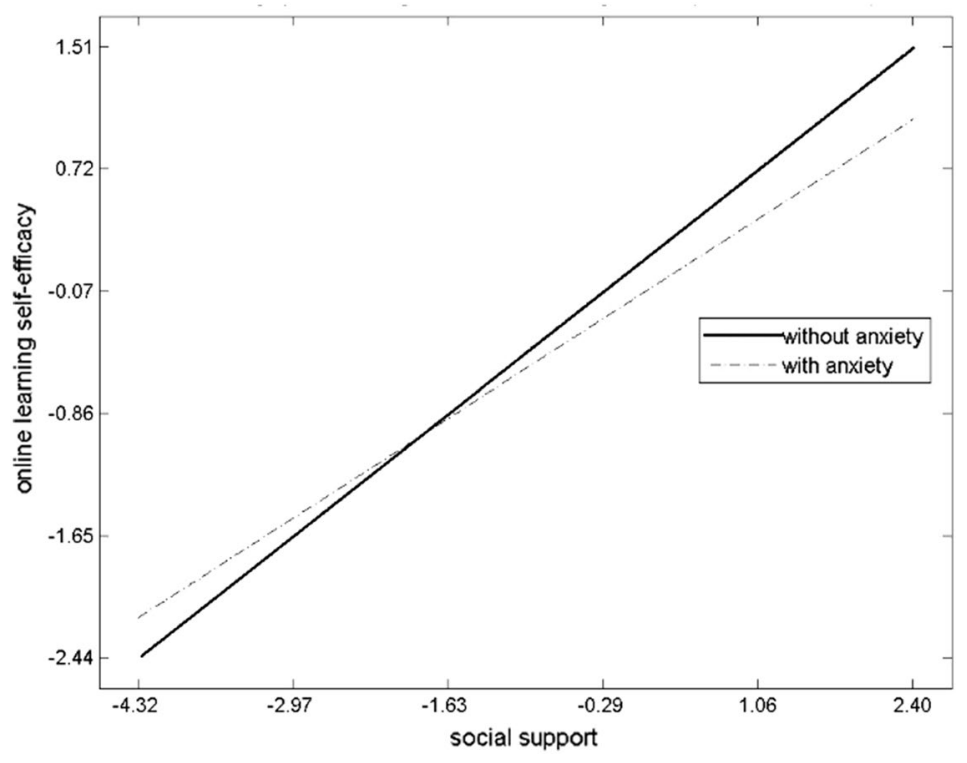

Fig. 2 Moderating effect of anxiety on the effect of social support on online learning self-efficacy

association has a medium effect size (i.e., $0.15 \leq \mathrm{f}^{2} \leq 0.350$ ) (Kock, 2017). Thus, Hypothesis 4 was supported.

Hypothesis 5a proposed that anxiety would moderate the positive relationship between social support and online learning self-efficacy. The result shows that the beta coefficient of the interaction term between social support and anxiety is negative and statistically significant $(\beta=-0.072 ; p<0.001)$. The result indicated that the positive relationship between social support and online learning self-efficacy was stronger among home-quarantined Chinese college students who perceived no anxiety than it was among those who felt anxiety. Given this result, Hypothesis 5a was supported. The result of this moderating effect is shown in Fig. 2.

Hypothesis $5 \mathrm{~b}$ proposed that anxiety would moderate the positive relationship between social support and well-being. The result shows that the beta coefficient of the interaction term between social support and anxiety is positive but not statistically supported $(\beta=0.005 ; p=0.386)$. This result indicated that the positive relationship between social support and well-being was not contingent on whether Chinese college students felt anxious or not. Therefore, Hypothesis $5 \mathrm{~b}$ was not supported.

Lastly, Hypothesis $5 \mathrm{c}$ proposed that anxiety would moderate the positive relationship between online learning self-efficacy and well-being. The result showed that the beta coefficient of the interaction term between social support and anxiety was negative $(\beta=-0.039 p=0.020)$. The result was statistically significant, meaning that the positive relationship between online learning self-efficacy and well-being was stronger among home-quarantined Chinese college students who felt no anxiety than it was among those who felt anxiety. Hence, Hypothesis $5 \mathrm{c}$ was supported. The result of this moderating effect is shown in Fig. 3. 


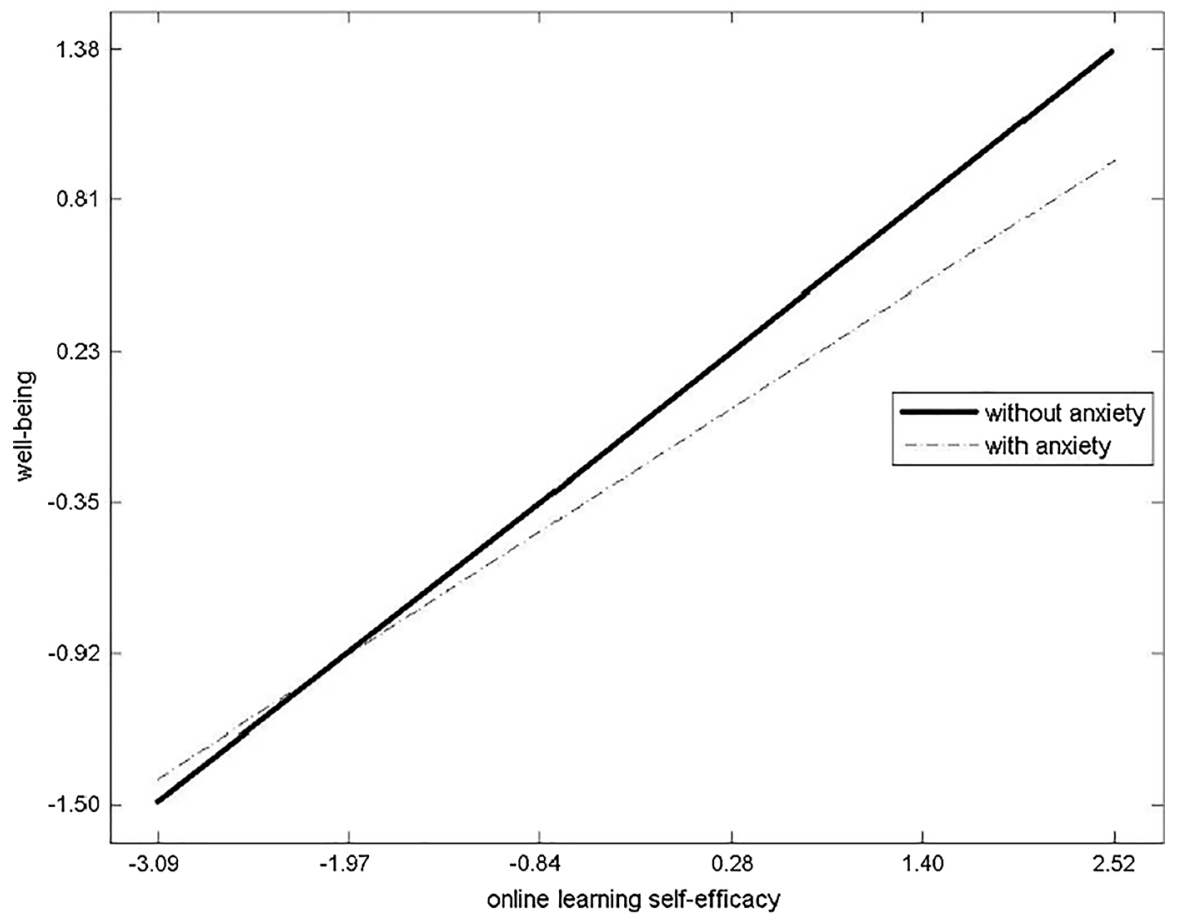

Fig. 3 Moderating effect of anxiety on the effect of online learning self-efficacy on well-being

\section{Discussion}

Many studies have identified both the direct and indirect relationship between social support and college students' well-being in general living and study contexts. This study examined whether social support was a significant predictor of home-quarantined Chinese college students' well-being during the COVID-19 pandemic. In addition, considering the fact that these college students were engaged in a unique online learning context, we investigated the role of factors unique to online learning contexts in our study. Specifically, we examined the mediating effect of online learning self-efficacy on the relationship between social support and well-being, and whether the strength of the one-on-one relationships among social support, online learning self-efficacy and well-being would diverge between home-quarantined Chinese college students with and without anxiety. Most of the current results support previous viewpoints on the contribution of social support and academic self-efficacy on college students' well-being; but more importantly, an investigation of the mediating role of online learning self-efficacy makes several unique contributions to our understanding of home-quarantined college students' well-being in online learning contexts.

Firstly, the current result provided empirical evidence for the role of social support as a predictor of home-quarantined college students' well-being during the COVID-19 pandemic. This finding aligned with prior studies which had reported 
the positive association between social support and college students' psychological and physical health in general living and study contexts (Karatekin \& Ahluwalia, 2020; C.-Y. S. Lee et al., 2020). This finding addressed the important role of social support as a social/environmental resource in influencing home-quarantined college students' well-being in non-normal living and study contexts, adding to the applicability and explanatory power of social support in diverse living and study contexts.

Secondly, our research was the first to identify a significantly positive association between social support and online learning self-efficacy. This result indicated that home-quarantined Chinese college students who perceived more social support were more confident in their abilities of learning online, time management and technology use when they had to take all the scheduled courses online. This result advanced previous research findings about the positive link between social support and general academic self-efficacy (Cicognani, 2011) by addressing the relationship between social support and self-efficacy specific to online-learning contexts.

Thirdly, we found that online learning self-efficacy was a significant indicator of home-quarantined Chinese college students' well-being during the COVID-19 pandemic. Although scarce research has explored the association between online learning self-efficacy and online learners' well-being, this finding was supported by previous research findings which confirmed that general self-efficacy was a strong predictor of people's well-being (Jin, Zhang, Wang, \& An, 2020; Salami, 2010; Singh \& Udainiya, 2009).Our research finding extended the current knowledge about self-efficacy by providing empirical evidence supporting that self-efficacy specific to online learning contexts could be a predictor of online learners' well-being.

Apart from this, we found a partial mediating role of online learning self-efficacy in the positive association between social support and home-quarantined Chinese college students' well-being. This partial mediating effect suggests that social support enhances home-quarantined students' online learning self-efficacy first, which is in turn conducive to their psychological and physical well-being. This finding highlighted the importance of online learning self-efficacy in explaining how social support could confer psychological and physical benefits for online learners. Online learning self-efficacy, specific to online learning contexts, can be effective on online learners' well-being in the same way as general academic self-efficacy in general study contexts. In support of the social support-academic self-efficacy-psychological well-being link, scholars argue that efficacious people are more likely to believe that they have reliable resources to cope with challenging and complex situations, hence, more able to maintain psychological and physical health (Riolli et al., 2012). In particular, our research is a response to calls for more research about the underlying mechanism explaining how social support can contribute to psychological and physical health (Wilson et al., 2020).

Lastly, our research found that for home-quarantined Chinese college students who perceived no anxiety, the positive relation between social support and online learning self-efficacy, as well as the positive association between online learning self-efficacy and well-being, was stronger than for those who perceived anxiety. It is interesting to note that the positive relation between social support and wellbeing does not differ between the two groups of college students. The sources of anxiety may be one possible reason for this phenomenon. As Table 1 shows, most 
of home-quarantined Chinese college students perceived sources of anxiety related to online learning, and only a few of them perceived anxiety directly related to COVID-19. Given this, anxiety can be a contingent factor influencing the strength of the relationships related to online learning self-efficacy but not the direct association between social support and well-being involving no online learning factors. This finding is consistent with prior studies which found that social support has a direct main effect on well-being even in the absence of specific sources of anxiety (Lakey $\&$ Orehek, 2011). That's why social support is positively related to well-being no matter home-quarantined Chinese college students perceive anxiety or not.

\section{Limitations}

There are some limitations to be addressed in this study. Firstly, this study may be subject to the generalizability problem. The research findings are limited to Chinese home-quarantined college students who learned online during the COVID-19 pandemic. Future researchers may test the model among the similar populations in different countries. Secondly, this study is limited in the use of cross-sectional data for relationship analysis. Hence, the relationships found in this study can only be interpreted as associations rather than causation. A longitudinal data collection design is warranted to better explain the effects of social support and online learning selfefficacy on well-being. Thirdly, this study may be subject to social desirability bias due to the use of self-evaluated question items.

\section{Conclusion}

To conclude, the current study identified social support as a significant predictor of home-quarantined Chinese college students' well-being during the COVID-19 pandemic. More importantly, this study highlights the important mediating role of online learning self-efficacy on the association between social support and college students' well-being in a home-quarantined online learning context. In addition, for home-quarantined Chinese college students who perceive no anxiety, the strength of the association of online learning self-efficacy with social support and well-being tends to be stronger than it was for those who perceived anxiety. Online learners' well-being interventions or therapies should incorporate social support and focus on the aspects of social support which facilitate the establishment and development of online learning self-efficacy in terms of online learning, time management and technology use.

Authors' contribution Both authors contributed to the study conception and design. Material preparation, data collection and analysis were performed by Jihong Zhou and Hongying Yu. The first draft of the manuscript was written by Jihong Zhou and Hongying Yu and both authors commented on previous versions of the manuscript. Both authors read and approved the final manuscript. 
Funding This study was supported by Jingmen City Education Sciences Planning Team under grant JMG2020002.

\section{Declarations}

Conflict of interest Both authors declare that they had no conflict of interest in conducting this research.

Availability of data and material Data are available upon request.

Ethics approval This study was conducted with the approval of the ethics committee of Jingchu University of Technology.

Consent to participate All participants agreed with the Free and Informed Consent form presented on the first page, attesting to voluntary participation.

Consent for publication All participants had information and agree about future publication.

\section{References}

Abdous, Mh (2019) Well begun is half done: Using online orientation to foster online students' academic self-efficacy. Online Learning, https://doi.org/10.24059/olj.v23i3.1437

Abdous, Mh. (2019a). Influence of satisfaction and preparedness on online students' feelings of anxiety. The Internet and Higher Education, 41, 34-44. https://doi.org/10.1016/j.iheduc.2019.01.001

Alghamdi, A., Karpinski, A. C., Lepp, A., \& Barkley, J. (2020). Online and face-to-face classroom multitasking and academic performance: Moderated mediation with self-efficacy for self-regulated learning and gender. Computers in Human Behavior, 102, 214-222. https://doi.org/10.1016/j.chb.2019. 08.018

Bandura, A. (2010). Self-efficacy. The Corsini encyclopedia of psychology, 1-3.

Bandura, A. (1977). Self-efficacy: Toward a unifying theory of behavioral change. Psychological Review, 84(2), 191.

Bates, R., \& Khasawneh, S. (2007). Self-efficacy and college students' perceptions and use of online learning systems. Computers in Human Behavior, 23(1), 175-191. https://doi.org/10.1016/j.chb. 2004.04.004

Bo, H.-X., Li, W., Yang, Y., Wang, Y., Zhang, Q., Cheung, T., Xiang, Y.-T. (2020). Posttraumatic stress symptoms and attitude toward crisis mental health services among clinically stable patients with COVID-19 in China. Psychological medicine, 1-2.

Bronfenbrenner, U. (1979). The ecology of human development. US: Harvard University Press.

Cao, W., Fang, Z., Hou, G., Han, M., Xu, X., Dong, J., \& Zheng, J. (2020). The psychological impact of the COVID-19 epidemic on college students in China. Psychiatry Research, 287, 112934. https:// doi.org/10.1016/j.psychres.2020.112934

Chemers, M. M., Hu, L.-T., \& Garcia, B. F. (2001). Academic self-efficacy and first year college student performance and adjustment. Journal of Educational Psychology, 93(1), 55-64. https://doi.org/10. 1037/0022-0663.93.1.55

Chen, J. H., Bjorkman, A., Zou, J. H., \& Engstrom, M. (2019). Self-regulated learning ability, metacognitive ability, and general self-efficacy in a sample of nursing students: A cross-sectional and correlational study. Nurse Education in Practice, 37, 15-21. https://doi.org/10.1016/j.nepr.2019.04.014

Chin, W. W. (2010). How to write up and report PLS analyses. In Handbook of partial least squares (pp. 655-690): Springer.

Cicognani, E. (2011). Coping strategies with minor stressors in adolescence: Relationships with social support, self-efficacy, and psychological well-being. Journal of Applied Social Psychology, 41(3), 559-578.

Cohen, S., Underwood, L. G., \& Gottlieb, B. H. (2000). Social support measurement and intervention: A guide for health and social scientists. UK: Oxford University Press. 
Crockett, L. J., Iturbide, M. I., Torres Stone, R. A., McGinley, M., Raffaelli, M., \& Carlo, G. (2007). Acculturative stress, social support, and coping: Relations to psychological adjustment among Mexican American college students. Cultural Diversity and Ethnic Minority Psychology, 13(4), 347.

Feeney, B. C., \& Collins, N. L. (2015). A new look at social support: A theoretical perspective on thriving through relationships. Personality and Social Psychology Review, 19(2), 113-147. https://doi. org/10.1177/1088868314544222

Flesia, L., Fietta, V., Colicino, E., Segatto, B., \& Monaro, M. (2020). Stable psychological traits predict perceived stress related to the COVID-19 outbreak through stable psychological traits and machine learning models. Journal of clinical medicine, 9(10), 3350.

Fornell, C., \& Larcker, D. F. (1981). Evaluating structural equation models with unobservable variables and measurement error. Journal of marketing Research, 18, 39-50.

Hair, J. F., Black, W. C., Babin, B. J., Anderson, R. E., \& Tatham, R. L. (2006). Multivariate data analysis (Vol. 6). In: Upper Saddle River, NJ: Pearson Prentice Hall.

Hall, N. C., Chipperfield, J. G., Perry, R. P., Ruthig, J. C., \& Goetz, T. (2006). Primary and secondary control in academic development: Gender-specific implications for stress and health in college students. Anxiety, Stress, and Coping, 19(2), 189-210.

Henseler, J., Ringle, C. M., \& Sarstedt, M. (2015). A new criterion for assessing discriminant validity in variance-based structural equation modeling. Journal of the Academy of Marketing Science, 43(1), $115-135$.

Hodges, C. B. (2008). Self-efficacy in the context of online learning environments: A review of the literature and directions for research. Performance Improvement Quarterly, 20(3-4), 7-25. https://doi. org/10.1002/piq.20001

Hult, G. T. M., Ketchen, D. J., Griffith, D. A., Finnegan, C. A., Gonzalez-Padron, T., Harmancioglu, N., \& Cavusgil, S. T. (2008). Data equivalence in cross-cultural international business research: Assessment and guidelines. Journal of International Business Studies, 39(6), 1027-1044.

Jin, Y., Zhang, M., Wang, Y., \& An, J. (2020). The relationship between trait mindfulness, loneliness, regulatory emotional self-efficacy, and subjective well-being. Personality and Individual Differences, 154, 109650.

Karatekin, C., \& Ahluwalia, R. (2020). Effects of adverse childhood experiences, stress, and social support on the health of college students. Journal of Interpersonal Violence, 35(1-2), 150-172.

Kline, R. B. (2011). principles and practices of structural equation modeling. Guilford Press.

Kock, N. (2017). WarpPLS User Manual: Version 6.0. Laredo, TX: Script Warp Systems.

Kock, N. (2014). Advanced mediating effects tests, multi-group analyses, and measurement model assessments in PLS-based SEM. International Journal of e-Collaboration (IJeC), 10(1), 1-13.

Kock, N., \& Lynn, G. (2012). Lateral collinearity and misleading results in variance-based SEM: An illustration and recommendations. Journal of the Association for Information Systems, 13(7), $546-580$.

Kong, F., Zhao, J., \& You, X. (2012). Self-esteem as mediator and moderator of the relationship between social support and subjective well-being among Chinese University students. Social Indicators Research, 112(1), 151-161. https://doi.org/10.1007/s11205-012-0044-6

Kumaraswamy, N. (2013). Academic stress, anxiety and depression among college students: A brief review. International Review of Social Sciences and Humanities, 5(1), 135-143.

Lakey, B., \& Orehek, E. (2011). Relational regulation theory: A new approach to explain the link between perceived social support and mental health. Psychological Review, 118(3), 482-495. https://doi.org/ $10.1037 / \mathrm{a} 0023477$

Lee, C.-Y.S., Goldstein, S. E., Dik, B. J., \& Rodas, J. M. (2020). Sources of social support and gender in perceived stress and individual adjustment among Latina/o college-attending emerging adults. $\mathrm{Cul}$ tural Diversity and Ethnic Minority Psychology, 26(1), 134.

Lee, J.-Y., \& Ciftci, A. (2014). Asian international students' socio-cultural adaptation: Influence of multicultural personality, assertiveness, academic self-efficacy, and social support. International Journal of Intercultural Relations, 38, 97-105. https://doi.org/10.1016/j.ijintre1.2013.08.009

Lee, L., Petter, S., Fayard, D., \& Robinson, S. (2011). On the use of partial least squares path modeling in accounting research. International Journal of Accounting Information Systems, 12(4), 305-328.

Ma, C. M. (2019). The relationship between social support and life satisfaction among Chinese and ethnic minority adolescents in Hong Kong: the mediating role of positive youth development. Child Indicators Research, 1-21.

Nunnally, J. C. (1978). Psychometric theory (2nd ed.). McGraw-Hill.

Olson, M. H. (2015). Introduction to theories of learning. Routledge: Psychology Press. 
Organization, W. H. (2020). Emergencies: Novel coronavirus 2019. WHO.

Pan, P. J., Chang, S.-H., \& Yu, Y.-Y. (2005). A support group for home-quarantined college students exposed to SARS: Learning from practice. The Journal for Specialists in Group Work, 30(4), 363-374.

Rapp-McCall, L. A., \& Anyikwa, V. (2016). Active learning strategies and instructor presence in an online research methods course: Can we decrease anxiety and enhance knowledge? Advances in Social Work, 17(1), 1-14.

Renk, K., \& Smith, T. (2007). Predictors of academic-related stress in college students: an examination of coping, social support, parenting, and anxiety. Journal of Student Affairs Research and Practice. https://doi.org/10.2202/1949-6605.1829

Riolli, L., Savicki, V., \& Richards, J. (2012). Psychological capital as a buffer to student stress. Psychology, 3(12), 1202.

Ruthig, J. C., Haynes, T. L., Stupnisky, R. H., \& Perry, R. P. (2008). Perceived academic control: Mediating the effects of optimism and social support on college students' psychological health. Social Psychology of Education, 12(2), 233-249. https://doi.org/10.1007/s11218-008-9079-6

Saadé, R., Kira, D., \& Nebebe, F. (2013). The challenge of motivation in e-Learning: role of anxiety. Paper presented at the Proceedings of the Informing Science and Information Technology Education Conference.

Salami, S. O. (2010). Emotional intelligence, self-efficacy, psychological well-being and students attitudes: Implications for quality education. European Journal of Educational Studies, 2(3), 247-257.

Shen, D., Cho, M.-H., Tsai, C.-L., \& Marra, R. (2013). Unpacking online learning experiences: Online learning self-efficacy and learning satisfaction. The Internet and Higher Education, 19, 10-17. https://doi.org/10.1016/j.iheduc.2013.04.001

Shevlin, M., McBride, O., Murphy, J., Miller, J. G., Hartman, T. K., Levita, L., Stocks, T. V. (2020). Anxiety, depression, traumatic stress, and COVID-19 related anxiety in the UK general population during the COVID-19 Pandemic.

Singh, B., \& Udainiya, R. (2009). Self-efficacy and well-being of adolescents. Journal of the Indian Academy of Applied Psychology, 35(2), 227-232.

Soysa, C. K., \& Wilcomb, C. J. (2013). Mindfulness, Self-compassion, Self-efficacy, and Gender as Predictors of Depression, Anxiety, Stress, and Well-being. Mindfulness, 6(2), 217-226. https://doi.org/ 10.1007/s12671-013-0247-1

Stupnisky, R. H., Perry, R. P., Renaud, R. D., \& Hladkyj, S. (2013). Looking beyond grades: Comparing self-esteem and perceived academic control as predictors of first-year college students' well-being. Learning and Individual Differences, 23, 151-157. https://doi.org/10.1016/j.lindif.2012.07.008

Sun, J. C. Y., \& Rueda, R. (2012). Situational interest, computer self-efficacy and self-regulation: Their impact on student engagement in distance education. British Journal of Educational Technology, 43(2), 191-204.

Taylor, S. E. (2011). Social support: A review.

Tinajero, C., Martínez-López, Z., Rodríguez, M. S., \& Páramo, M. F. (2019). Perceived social support as a predictor of academic success in Spanish university students. Anales De Psicología, 36(1), 134142. https://doi.org/10.6018/analesps.344141

Tomás, J. M., Gutiérrez, M., Pastor, A. M., \& Sancho, P. (2020). Perceived social support, school adaptation and Adolescents' subjective well-being. Child Indicators Research. https://doi.org/10.1007/ s12187-020-09717-9

Tong, Y., \& Song, S. (2004). A study on general self-efficacy and subjective well-being of low SEScollege students in a Chinese university. College Student Journal, 38(4), 637-643.

Wang, C. C. D., \& Castañeda-Sound, C. (2008). The role of generational status, self-esteem, academic self-efficacy, and perceived social support in college students' psychological well-being. Journal of College Counseling, 11(2), 101-118.

Wilson, J. M., Weiss, A., \& Shook, N. J. (2020). Mindfulness, self-compassion, and savoring: Factors that explain the relation between perceived social support and well-being. Personality and Individual Differences. https://doi.org/10.1016/j.paid.2019.109568

Yavuzalp, N., \& Bahcivan, E. (2020). The Online learning self-efficacy scale: Its adaptation into turkish and interpretation according to various variables. Turkish Online Journal of Distance Education, $21(1), 31-44$

Yokoyama, S. (2019). Academic self-efficacy and academic performance in online learning: A mini review. Frontiers in Psychology, 9, 2794. 
Zander, L., Brouwer, J., Jansen, E., Crayen, C., \& Hannover, B. (2018). Academic self-efficacy, growth mindsets, and university students' integration in academic and social support networks. Learning and Individual Differences, 62, 98-107. https://doi.org/10.1016/j.lindif.2018.01.012

Zhang, Y., Wang, J., Zhao, J., Tanimoto, T., Ozaki, A., Crump, A., \& Yu, J. (2020). Association between quarantined living circumstances and perceived stress in Wuhan city during the COVID 19 Outbreak: A Rapid. Exploratory Cross-Sectional Study Exploratory Cross Sectional Study. https://doi. org/10.2139/ssrn.3556642

Zimet, G. D., Dahlem, N. W., Zimet, S. G., \& Farley, G. K. (1988). The multidimensional scale of perceived social support. Journal of Personality Assessment, 52(1), 30-41. https://doi.org/10.1207/ s15327752jpa5201_2

Zimmerman, W. A., \& Kulikowich, J. M. (2016). Online learning self-efficacy in students with and without online learning experience. American Journal of Distance Education, 30(3), 180-191.

Publisher's Note Springer Nature remains neutral with regard to jurisdictional claims in published maps and institutional affiliations.

Jihong Zhou is a Ph.D. of Management in Foreign Language Department at Jingchu University of Technology. Her research interests concern cognitions, emotions, and motivation in achievement settings, with a focus on the roles of social support, online learning strategies and self-efficacy in the academic development and wellbeing of students in online learning environments

Hongying Yu is an Associate Professor in Physical Education Department at Jingchu University of Technology. His research mainly focuses on psychosocial factors such as perceived control involved in achievement motivation, physical health, and psychological well-being of college students

\section{Authors and Affiliations}

\section{Jihong Zhou' ${ }^{1} \cdot$ Hongying $\mathrm{Yu}^{2}$}

Hongying Yu

yhy97017@126.com

1 Foreign Language School, Jingchu University of Technology, Xiangshan Avenue 33, Jingmen 448000, Hubei, People's Republic of China

2 Physical Education Department, Jingchu University of Technology, Xiangshan Avenue 33, Jingmen 448000, Hubei, People's Republic of China 